4 Barth, C. A., Hord, C. W., Pearce, J. B., Kelly, K. K., Anderson, G. P., and Stewart, A. I., J. geophys. Res., 76, 22132227 (1971).

5 Opal, C., and Carruthers, G., IAU Circ. No. 2618 (1974).

${ }^{6}$ Keenan, P. C., and Hynek, J. A., Astrophys. J., 111, 1-10 (1950).

${ }^{7}$ Biermann, L., $Q$. Jl R. astr. Soc., 12, 417-432 (1971).

${ }^{8}$ Keller, H., Astr. Astrophys., 23, 269-280 (1973).

9 Comes, F. J., Speier, F., and Elzer, A., Z. Naturf., 23A, $125-133(1968)$

${ }^{10}$ Fite, W. L., Smith, A. C. H., and Stebbings, R. F., Proc. $R$. Soc., A268, 527-536 (1962).

${ }^{11}$ Wiese, W. L., Smith, M. W., and Glennon, B. M., Atomic Transition Probabilities, NSRDS-NBS 4, 1, (US Government Printing Office, Washington, 1966).

12 Biermann, L., Joint Institute for Laboratory Astrophysics, Report No. 93, (Univ. Colorado, Boulder, 1968).

${ }^{13}$ Donn, B., IAU Circ. No. 2605 (1973).

\section{PAN over the Atlantic and the smell of clean linen}

Ozone, at concentrations in excess of 0.1 parts per million (p.p.m.), has been observed in the summertime air over southern England ${ }^{1}$. The most probable source is photochemical reaction among air pollution products. We therefore sought the presence of another characteristic product of urban atmospheric photochemistry ${ }^{2}$, peroxy acetyl nitrate (PAN). Preliminary measurements (S. A. Penkett and F. J. Sandalls, personal communication) show that PAN is present in the air over southern England. During episodes of increased ozone and other atmospheric pollution indicators the concentration increased, but as with ozone there was always a background concentration of PAN even in clean air arriving from the Atlantic. The voyage of the German Research Vessel Meteor from Hamburg to Santo Domingo in October 1973 presented an opoprtunity to discover whether or not there is a natural background of PAN.

Analysis was by gas chromatography using an electron capture detector. Air samples were collected at the bows of the ship by drawing $5 \mathrm{ml}$ of air into a glass syringe; the sample was then quickly injected into the gas chromatograph. The apparent concentration of PAN during the voyage is shown in Fig. 1 . Concentrations of $\mathrm{CCl}_{3} \mathrm{~F}$ are also included because increases in the background level of this compound indicate the presence of air from urban industrial regions ${ }^{3}$. The term 'apparent' is used because it was discovered during the voyage that the unexpectedly high concentrations over the Atlantic were not present in the air, as such, but had formed by reaction on the glass surface of the sampling syringe. No PAN could be detected in air collected in polypropylene syringes, but the addition of a twist of glass wool to such syringes before the air was drawn into them restored the concentration to levels similar to those found with glass syringes. One-litre samples of fresh air were also drawn through plugs containing $1 \mathrm{~g}$ of glass or cotton wool, and these were found to be strong sources of PAN and of peroxy proprionyl nitrate (PPN). In addition the wools possessed the characteristic bleachlike odour of linen after it has been dried in the open air. The PAN potentials of Fig. 1 are approximate and probably too low. No corections were made for losses by adsorption or for the extent to which the detector was not coulometric.

The potential for formation of PAN was most marked on days of unobstructed sunshine (see Fig. 1). October 13 and 14 , when the ship passed through a polluted air mass (which was indicated by the high concentrations of $\mathrm{CCl}_{3} \mathrm{~F}$ ) were exceptions. PAN formation was greatest at approximately $1400 \mathrm{~h}$ and was between 3 and 10 times lower at dawn and in the evening. Simultaneous measurements from the ship, of the aerial concentration of atmospheric hydrocarbons, indicated levels of betwen 0.1 and 2 parts per $10^{9}$ (p.p.b.) for the lower unsaturated hydrocarbons (R. A. Rasmussen, personal communication). The sea was apparently the most probable source. The concentration of

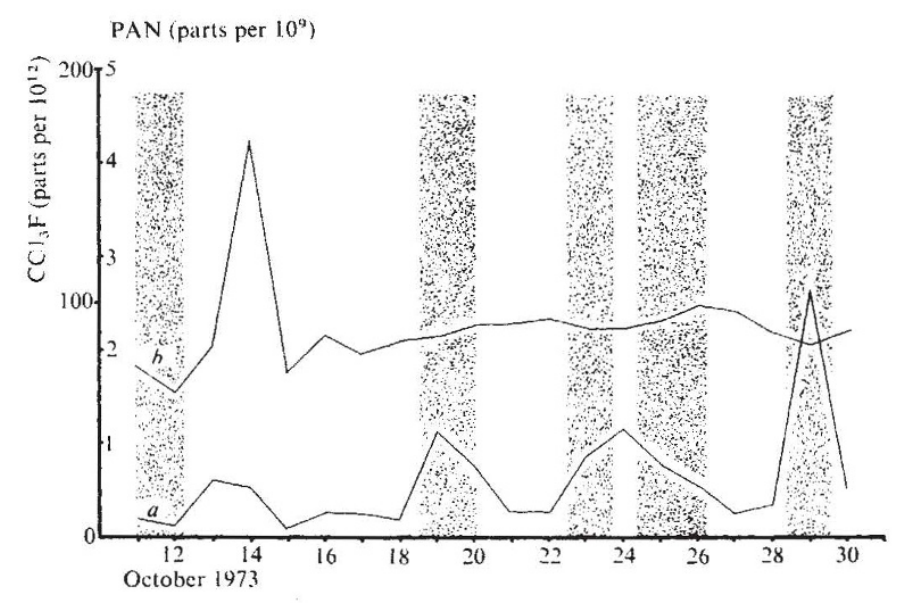

Fig. 1 PAN from the air over the Atlantic. Average daily concentrations of 'apparent' PAN $\times 10^{-9}(a)$ and $\mathrm{CCl}_{3} \mathrm{~F} \times 10^{-12}(b)$ by volume. Shaded columns indicate days with less than $50 \%$ cloud cover.

the other ingredients necessary to form PAN by photochemical reaction were not measured. Ozone is ubiquitous and can be presumed to have been present in at least its background concentration of about 50 p.p.b.

These preliminary observations suggested that PAN and similar compounds can be formed in the clean air of remote maritime regions by heterogeneous reaction if a suitable surface is provided. They raise some interesting and important questions. What are the mid-Atlantic precursors? Is PAN formation in urban photochemical smog also by heterogeneous reaction? If so what is the surface on which it forms? Finally the quantities of PAN observed suggest the presence of a high background concentration of $\mathrm{NO}_{x}$ or of some related molecular species.

We are grateful to the Deutsche Hydrographische Institut and the Captain, Officers and men of the Meteor for the opportunity for one of us (J.E.L.) to voyage with the ship. We thank Shell Research Ltd. and the Natural Environment Research Council for their financial support.

JAMES E. LOVELock

Department of Applied Physical Sciences,

Reading University,

Whiteknights,

Reading RG6 $2 A L, U K$

Stuart A. Penkett

Health Physics and Medical Division,

Atomic Energy Research Establishment, Harwell, Berkshire, UK

Received March 6, 1974.

1 Atkins, D. H. F., Cox, R. A., and Eggleton, A. E. J., Nature, 235, 372 (1972).

2 Scott, W. E., Stephens, E. R., Hanst, T. L., Doerr, R. C., Proc. Am. Petrol. Inst., Sec. III, 37, 171 (1957)

${ }^{3}$ Lovelock, J. E., Atmos. Environ., 6, 917-925 (1972). 